\title{
BDNF-Hypersecreting Human Mesenchymal Stem Cells Promote Functional Recovery, Axonal Sprouting, and Protection of Corticospinal Neurons after Spinal Cord Injury
}

\author{
Masanori Sasaki, ${ }^{1,2,3}$ Christine Radtke, ${ }^{1,2,6}$ Andrew M. Tan, ${ }^{1,2}$ Peng Zhao, ${ }^{1,2}$ Hirofumi Hamada, ${ }^{4}$ Kiyohiro Houkin, ${ }^{3}$ \\ Osamu Honmou, ${ }^{1,2,3,5}$ and Jeffery D. Kocsis ${ }^{1,2}$ \\ ${ }^{1}$ Department of Neurology and Center for Neuroscience and Regeneration Research, Yale University School of Medicine, New Haven, Connecticut 06510, \\ ${ }^{2}$ Neuroscience and Regeneration Research Center, VA Connecticut Healthcare System, West Haven, Connecticut 06516, Departments of ${ }^{3}$ Neurosurgery, \\ ${ }^{4}$ Molecular Medicine, and ${ }^{5}$ Neural Repair and Therapeutics, Sapporo Medical University School of Medicine, Sapporo, Hokkaido 060-8543, Japan, and \\ ${ }^{6}$ Department of Plastic, Hand and Reconstructive Surgery, Medizinische Hochschule Hannover, 30625 Hannover, Germany
}

Transplantation of mesenchymal stem cells (MSCs) derived from bone marrow has been shown to improve functional outcome in spinal cord injury (SCI). We transplanted MSCs derived from human bone marrow (hMSCs) to study their potential therapeutic effect in SCI in the rat. In addition to hMSCs, we used gene-modified hMSCs to secrete brain-derived neurotrophic factor (BDNF-hMSCs). After a dorsal transection lesion was induced at T9, cells were microinjected on each side of the transection site. Fluorogold (FG) was injected into the epicenter of the lesion cavity to identify transected corticospinal tract (CST) neurons. At 5 weeks after transplantation, the animals were perfused. Locomotor recovery improvement was observed for the BDNF-hMSC group, but not in the hMSC group. Structurally there was increased sprouting of injured corticospinal tract and serotonergic projections after hMSC and BDNF-hMSC transplantation. Moreover, an increased number of serotonergic fibers was observed in spinal gray matter including the ventral horn at and below the level of the lesion, indicating increased innervation in the terminal regions of a descending projection important for locomotion. Stereological quantification was performed on the brains to determine neuronal density in primary motor (M1) cortex. The number of FG backfilled cells demonstrated an increased cell survival of CST neurons in M1 cortex in both the hMSC and BDNF-hMSC groups at 5 weeks, but the increase for the BDNF-hMSC group was greater. These results indicate that transplantation of hMSCs hypersecreting BDNF results in structural changes in brain and spinal cord, which are associated with improved functional outcome in acute SCI.

\section{Introduction}

Transplantation of bone marrow-derived cells into spinal cord injury (SCI) models has been reported to promote axonal regeneration, reduce lesion size, and improve functional outcome (Chopp et al., 2000; Hofstetter et al., 2002; Ankeny et al., 2004; Kamada et al., 2005; Cízková et al., 2006; Himes et al., 2006:

Received June 12, 2009; accepted 0ct. 6, 2009.

This work was supported in part by the Medical and Rehabilitation and Development Research Services of Department of Veterans Affairs (VA), the VA Spinal Cord Injury Translational Collaborative Consortium for Regenerative Medicine, the National Institutes of Health (NS43432 to J.D.K.), the National Multiple Sclerosis Society (RG2135; CA1009A10 to J.D.K.), the Bumpus Foundation, the Paralyzed Veterans of America Research Foundation (2469 to M.S.), the Connecticut Stem Cell Research Grants Program (08-SCA-YSME-011 to M.S.), and the Japanese Ministry of Education, Science, Sports and Culture (19591691, 20390388, 20591717 to 0.H.). This material is based upon work supported by the State of Connecticut under the Connecticut Stem Cell Research Grants Program. Its contents are solely the responsibility of the authors and do not necessarily represent the official views of the State of Connecticut, the Department of Public Health of the State of Connecticut, or Connecticut Innovations, Incorporated. The Center for Neuroscience and Regeneration Research is a collaboration of the Paralyzed Veterans of America and the United Spinal Association with Yale University. We thank Heather Mallozzi, Margaret Borelli, and Cynthia Santaniello for excellent animal care and technical assistance, Dr. Bryan Hains for contribution in the initial study, and Drs. Edgardo Arroyo and Yu-Wen Chang for assistance with confocal microscopy.

Correspondence should be addressed to either Dr. Masanori Sasaki or Dr. Jeffery D. Kocsis, Department of Neurology, Yale University School of Medicine, Neuroscience Research Center (127A), VA Connecticut Health Care System, West Haven, CT 06516, E-mail: masanori.sasaki@yale.edu or jeffery.kocsis@yale.edu.

DOI:10.1523/JNEUROSCI.2769-09.2009

Copyright $\odot 2009$ Society for Neuroscience $\quad 0270-6474 / 09 / 2914932-10 \$ 15.00 / 0$
Shichinohe et al., 2008; Someya et al., 2008; Zurita et al., 2008). The precise cell type within bone marrow responsible for these beneficial effects is not fully established but is thought to reside within the marrow stromal or mesenchymal stem cell (MSC) population (Li et al., 2002; Iihoshi et al., 2004). MSCs can be isolated and expanded as plastic adherent cells having a flattened fibroblast-like morphology (Friedenstein, 1976; Woodbury et al., 2000) that are $\mathrm{CD} 34^{-}, \mathrm{CD} 45^{-}, \mathrm{SH} 2^{+}$, and $\mathrm{SH}_{3}{ }^{+}$(Majumdar et al., 1998; Kobune et al., 2003). MSCs have been suggested to differentiate in culture into osteoblasts, chondrocytes, adipocytes, and hepatocytes (Prockop, 1997; Pittenger et al., 1999; Sanchez-Ramos et al., 2000; Krause et al., 2001; Kobune et al., 2003) and neuronal and glial lineages (Azizi et al., 1998; Kopen et al., 1999; Brazelton et al., 2000; Sanchez-Ramos et al., 2000; Woodbury et al., 2000; Iihoshi et al., 2004). However, current thinking is that the potential beneficial effect of MSCs in various models of CNS injury is not from neuronal or glial differentiation but from release of trophic factors which can provide for neuroprotection (Chen et al., 2002; Parr et al., 2007), induction of axonal sprouting (Shen et al., 2006), neovascularization (Onda et al., 2008), and immunomodulation (Ohtaki et al., 2008; Bai et al., 2009). The release of trophic factors from transplanted hMSCs or stimulation of their endogenous production within the host spi- 
nal cord may contribute to the recovery of function following SCI (Chen et al., 2002; Lu et al., 2005; Koda et al., 2007).

Isolated cultured bone marrow-derived MSCs can secrete trophic factors (Hamano et al., 2000; Chen et al., 2002; Iihoshi et al., 2004; Kurozumi et al., 2004) including brain-derived neurotrophic factor (BDNF), nerve growth factor (NGF), vascular endothelial growth factors (VEGF), and hepatocyte growth factor (HGF). BDNF is of particular interest because it has been shown to promote survival and sprouting of corticospinal tract (CST) neurons after axotomy (Namiki et al., 2000; Hiebert et al., 2002; Zhou and Shine, 2003). BDNF applied to cortex after SCI led to preservation of CST neurons and to collateral sprouting with increased number of contacts with propriospinal interneurons (Vavrek et al., 2006), which are important in functional recovery after SCI by their ability to increase axonal contacts on motor neurons below the spinal cord lesion (Bareyre et al., 2004).

In this study, we transplanted both hMSCs and genetically modified hMSCs that express BDNF (BDNF-hMSCs) into a rat SCI model to investigate the impact of cellular delivery of BDNF by hMSCs on functional outcome, axonal regeneration, and neuroprotection in acute SCI.

\section{Materials and Methods}

Preparation of hMSCs. Human bone marrow from healthy adult volunteers was obtained by aspiration from the posterior iliac crest after informed consent was obtained; this study was approved by the institutional review board at Sapporo Medical University, Japan (Kobune et al., 2003). Bone marrow mononuclear cells were isolated, plated in $150 \mathrm{~cm}^{2}$ plastic tissue culture flasks and incubated overnight. After the free cells were washed away, the adherent cells were cultured in mesenchymal stem cell basal medium (MSCBM, Cambrex) containing mesenchymal cell growth supplement (MCGS, Cambrex) with 4 mu L-glutamine and kept in a humidified atmosphere of $5 \% \mathrm{CO}_{2}$ at $37^{\circ} \mathrm{C}$. After reaching confluency, they were harvested and cryopreserved as primary MSCs or used for gene transduction.

Adenoviral vectors. Adenoviral vectors carrying a human BDNF cDNA were constructed as described previously (Kurozumi et al., 2004; Nomura et al., 2005). Briefly, human BDNF cDNA was cloned using the reverse transcription-PCR method from the total RNA extracted from primary hMSC as the template. The identity of BDNF cDNA obtained in this manner was confirmed by sequencing and comparing it to the GenBank sequence XM_006027.

The human BDNF primer sequences were as follows: forward, $5^{\prime}$-CGGAATTCCACCATGACCATCCTTTTCCTTACTATGGTTA-3'; and reverse, 5' -CCAGATCTATCTTCCCCTTTTAATGGTCAATGTA-3'.

The BDNF cDNA was inserted between the EcoRI site and the BgIII site in the pCAcc vector, and the resulting plasmid was designated pCAhBDNF. The plasmid pCAhBDNF was digested with ClaI, and the fragment containing the BDNF cDNA expression unit was isolated by agarose gel electrophoresis. The adenoviral BDNF expression vector, pWEAxCAhBDNF-F/RGD, was prepared using Lipofectamine 2000 (Invitrogen). Before being used, the above viral vectors were evaluated for their viral concentration and titer, and viral stocks were examined for potential contamination with replication-competent viruses. To determine viral concentration [particle unit $(\mathrm{pu}) / \mathrm{ml}$ ], the viral solution was incubated in $0.1 \%$ SDS and $A_{260}$ was measured. The viral titers of AxCAhBDNF-F/RGD were $1.0 \times 10^{12} \mathrm{pu} / \mathrm{ml}$.

Adenovirus infection. Adenovirus-mediated gene transfection was performed as previously described (Nomura et al., 2005). Briefly, the cells were seeded at a density of $2 \times 10^{6}$ cells per $15 \mathrm{~cm}$ plate. MSCs were exposed to the infectious viral particles in $7.5 \mathrm{ml}$ DMEM at $37^{\circ} \mathrm{C}$ for 60 min; cells were infected with AxCAhBDNF-F/RGD at a multiplicity of infection (MOI) of $3.0 \times 10^{3} \mathrm{pu} / \mathrm{cell}$. The medium was then removed, and the cells were washed once with DMEM and then recultured with normal medium for $12 \mathrm{~h}$, after which transplantation was performed. Commercial BDNF ELISA kits (Promega) were used to quantify the concentration of BDNF in the supernatant of cultured BDNF-hMSCs with an MOI of $3.0 \times 10^{3} \mathrm{pu} / \mathrm{cell}$ at a rate of $4.73 \pm 0.59 \mathrm{ng} / 10^{5} \mathrm{cells} / 48 \mathrm{~h}$ (Nomura et al., 2005).

Phenotypic characterization of the hMSCs and BDNF-hMSC. Flow cytometric analyses of primary hMSCs and BDNF-hMSCs were performed as described previously (Honma et al., 2006; Liu et al., 2006; Onda et al., 2008). Briefly, cell suspensions were washed twice with PBS containing $0.1 \%$ bovine serum albumin. For direct assays, aliquots of cells at a concentration of $1 \times 10^{6}$ cells $/ \mathrm{ml}$ were immunolabeled at $4^{\circ} \mathrm{C}$ for $30 \mathrm{~min}$ with the following anti-human antibodies: fluorescein isothiocyanate (FITC)-conjugated CD45, CD34, CD105 (Immunotech), and antihuman CD73 (SH-3; BD Biosciences PharMingen). As an isotypematched control, mouse IgG1-FITC (IgG1-FITC; Immunotech) was used. Labeled cells were analyzed by a FACSCalibur flow cytometer (Becton Dickinson) using CellQuest software. Dead cells were gated out with forward- versus side-scatter window and propidium iodide staining.

PKH26 labeling. Cells were prelabeled with the membrane dye PKH26 according to the manufacturer's instructions (Sigma-Aldrich). The efficiency of cellular labeling (routinely 100\%) was examined with a fluorescence microscope.

Animals. Experiments were performed in accordance with National Institutes of Health (NIH) Guidelines for the Care and Use of Laboratory Animals, and the VA Connecticut Healthcare System Institutional Animal Care and Use Committee approved all animal protocols. Adult female Sprague Dawley rats $(n=66)(150-179 \mathrm{~g})$ were anesthetized with ketamine/xylazine (90/4 mg/kg, i.p.). Under sterile technique, a T9 laminectomy was performed, and dura was opened to expose the spinal cord. The dorsal vein of the spinal cord was coagulated, and the dorsal funiculus was transected using an ophthalmic microscalpel (P-715; Feather Safety) (Sasaki et al., 2004). The microscalpel blade was marked for a 1.0 $\mathrm{mm}$ depth of cut across the entire dorsal region of the spinal cord. This lesion shows consistent damage to the spinal cord from animal to animal as observed with plastic embedded semithin toluidine blue sections (Sasaki et al., 2004). After the cell injection, Gelfoam (Pharmacia and Upjohn) impregnated with $5 \mu$ l of Fluorogold (FG; $4 \%$ w/v in saline, $\mathrm{pH}$ 7.4; Invitrogen), was placed into the epicenter of the lesion cavity (Hains et al., 2003; Sasaki et al., 2006). The overlying muscles and skin were closed in layers with 4-0 nylon sutures, and the animal was allowed to recover on a $37^{\circ} \mathrm{C}$ heating pad. This surgery resulted in paresis of the hindlimbs in all animals subjected to the procedure but did not impair eating, drinking, or elimination.

hMSC, BDNF-hMSC transplantation. Immediately after transection of the dorsal funiculus, the cells were injected into the dorsal funiculus by using a drawn glass micropipette (Sasaki et al., 2006). Two injections were made at $\sim 0.5 \mathrm{~mm}$ rostral and two at $0.5 \mathrm{~mm}$ caudal to the lesion at depths of 0.7 and $0.4 \mathrm{~mm}\left(1.0 \mu \mathrm{l}\right.$ per site; $3.0 \times 10^{4}$ cells $/ \mu \mathrm{l}$ for a total of $1.2 \times 10^{5}$ cells transplanted per rat). Transplant-receiving rats and medium (DMEM)-injected rats were immunosuppressed with Cyclosporin A $(10 \mathrm{mg} / \mathrm{kg} / \mathrm{d})$ beginning $1 \mathrm{~d}$ before surgery and continued daily for the survival duration. Experimental condition was as follows: PKH26labeled hMSCs $(n=10)$, PKH26-labeled BDNF-hMSCs $(n=10)$, media $(\mathrm{DMEM})(n=10), \mathrm{FG}$ plus hMSCs $(n=6), \mathrm{FG}$ plus BDNF-hMSCs $(n=$ $6)$, FG plus DMEM $(n=6)$, hMSC $(n=6)$, BDNF-hMSC $(n=6)$, $\operatorname{DMEM}(n=6)$.

Open-field locomotor testing. Behavioral analysis was performed $(n=$ 16 animals/group). Intact animals $(n=6)$ were tested for control. Preoperative testing began $2 \mathrm{~d}$ before injury and was performed at $3 \mathrm{~d}$ and weekly for 5 weeks after surgery. Locomotor function was recorded by a blinded observer using the Basso-Beattie-Bresnahan (BBB) locomotor rating scale (Basso et al., 1995) to ensure reliability of hind limb somatosensory testing and to assess treatment outcome. Values displayed are means \pm SEM.

Rotarod testing. Another subset of locomotor function was assessed for their sensory-motor ability using a motorized Rotarod system and Rotamex software package, version 1.32A (Columbus Instruments). Performance was then tested at 5 weeks postsurgery. The rod (diameter, $7.0 \mathrm{~cm}$ ) was accelerated at $0.1 \mathrm{rpm} / \mathrm{s}$ and increased in speed from 5 to $30 \mathrm{rpm}$ at a constant rate of acceleration over $3 \mathrm{~min}$. Scores (maximum rpm achieved, total run time) were averaged over three trials per session (Tan et al., 2008). 
Immunohistochemistry procedures. Animals were perfused transcardially with $0.9 \%$ saline, followed by $4 \%$ paraformaldehyde in $0.14 \mathrm{M}$ Sorensen's buffer; brain and spinal cord tissue were cryoprotected overnight at $4^{\circ} \mathrm{C}$ in $30 \%$ sucrose. Sixteen micrometer longitudinal cryosections of the spinal cord were cut and mounted on Sigma Silane-Prep glass slides, and the sections were processed for immunolabeling for monoclonal TUJ-1 (1/100; Millipore), monoclonal GFAP (1/1000; Sigma), and polyclonal NG2 (1/200; Millipore). Secondary antibodies used were goat anti-mouse IgGAlexa Fluor 488 (1:1000; Invitrogen) and goat anti-rabbit IgG-Alexa Fluor 488 (1:1000; Invitrogen), and they were mounted with Vectashield mounting medium for fluorescence with DAPI (4',6-diamidino-2-phenylindole; Vector Labs). The sections were examined under a fluorescence scope equipped with confocal lasers (Zeiss LSM510). Images were captured using LSM 510 software (Zeiss) and arranged using CorelDRAW 12 (Corel) and Photoshop (Adobe Systems).

$P K C-\gamma$ staining. The spinal cord $(n=$ 5/group) 5-10 $\mathrm{mm}$ rostral to and 5-10 $\mathrm{mm}$ caudal to the lesion center was embedded in OCT (Triangle Biomedical Sciences). Fivemillimeter-length blocks of spinal cord from T7 and T8 were frozen in OCT and 160 serial sections ( $8 \mu \mathrm{m}$ thick) in the coronal plane were cut using a 2800 Frigocut (GMI) cryostat and thaw mounted onto gelatinized glass slides. The sections were washed in blocking solution [potassium PBS (KPBS), 0.1\% Triton X-100, $4 \%$ normal donkey serum] and incubated overnight at $4^{\circ} \mathrm{C}$ in rabbit anti-protein kinase C-gamma (PKC- $\left.\gamma\right)(1: 500$; Santa Cruz Biotechnology) diluted in the same blocking solution. After being washed in blocking solution, sections were incubated for $1 \mathrm{~h}$ in donkey anti-rabbit Alexa Fluor 488 (1:2000; Invitrogen) at room temperature. Slides were washed in clean KPBS and coverslipped with Aqua Polymount mounting solution (Polysciences). Sections were visualized with a Nikon Eclipse E800 microscope with an HQ Coolsnap camera (Roper Scientific) (Barritt et al., 2006).

Image analysis was performed similarly to Barritt et al. (2006). Four coronal sections were selected for analysis. MetaVue software (Scanalytics) was used to calculate relative intensity of PKC- $\gamma$ immune-positive signal intensity within three bins $(300 \times 200 \mu \mathrm{m})$. These bins were superimposed over the dorsal columns avoiding the superficial gray matter of the dorsal horn. Using unstained tissue to normalize for background signals, digital images were processed into binary images through a threshold algorithm across groups. The mean pixel density within each bin was calculated within each group and expressed as a percentage of fields (pixel area/total bin area). Each bin was statistically compared against the control treated group.

5-HT staining. The spinal cord ( $n=5 /$ group) $5-10 \mathrm{~mm}$ rostral to and 5-10 $\mathrm{mm}$ caudal to the lesion center was embedded in a glutaraldehyde-polymerized albumin matrix and cut parasagittally in the thickness of $40 \mu \mathrm{m}$ on a vibratome. Transverse sections $(40 \mu \mathrm{m})$ were collected from the spinal cord 11-16 $\mathrm{mm}$ rostral to and 11-16 $\mathrm{mm}$ caudal to the lesion center. For analysis of serotonin innervation, the sections were incubated with avidin-biotin-peroxidase complex plus anti-5-HT antibody (1:10,000; Immunostar) to detect raphespinal fibers (Wang et al., 2006). Immunoreactive serotonin fibers in the ventral horn of transverse sections rostral or caudal to the lesion center were photographed using conventional fluorescence microscopy (Nikon Eclipse 800; Spot RT Color CCD camera; Diagnostic Instruments). Immunoreactivity was quantified using NIH Scion Image software to count
hMSC

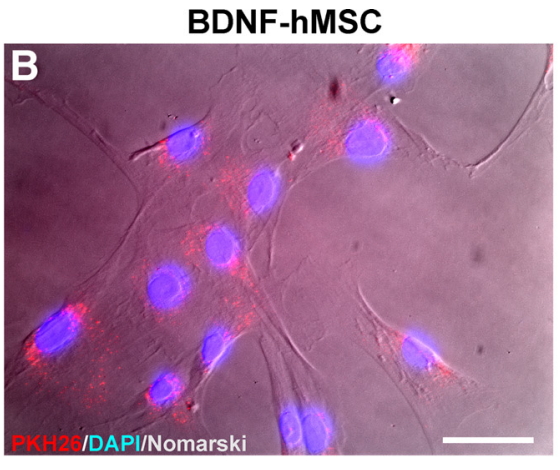

D
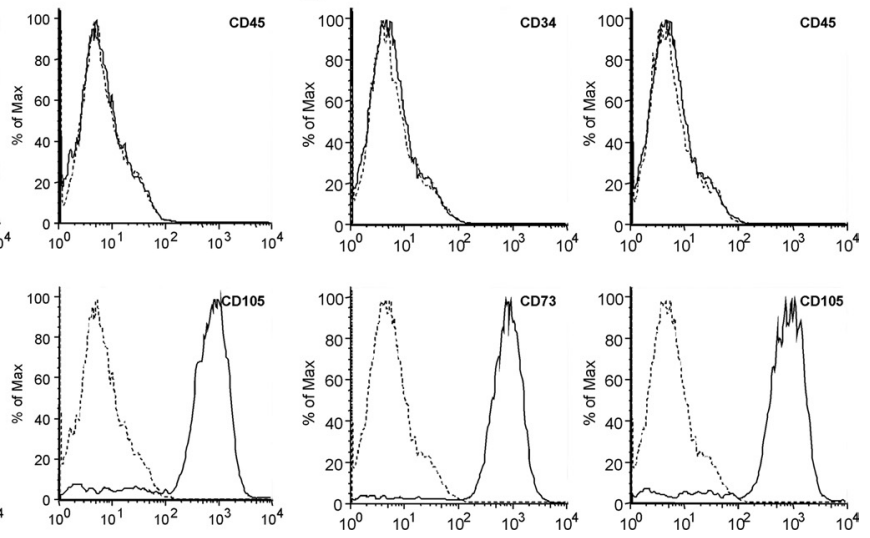

$A, B$, Merged Nomarski light and fluorescent images of PKH26labeled hMSCs $(\boldsymbol{A})$ and BDNF-hMSCS $(\boldsymbol{B})$ counterstained with DAPI in vitro. $\boldsymbol{C}, \boldsymbol{D}$, Flow cytometric analysis of surface antigen expression on primary hMSCS $(\boldsymbol{C})$ and BDNF-hMSCS $(\boldsymbol{D})$. The cells were immunolabeled with FITC-conjugated monoclonal antibody specific for the indicated surface antigen. Dead cells were eliminated by forward and side scatter. Scale bar: (in $B) A, B, 5 \mu \mathrm{m}$.

the number of immunopositive pixels set above a threshold to selectively detect serotonin immunoreactivity. The total number of immunoreactive pixels was averaged to represent the 5-HT immunoreactivity for each animal (Lee et al., 2007).

Physical disector counting method and image analysis. Stereologic counting methods were used to obtain an accurate estimate of the number of FG-labeled backfilled neurons after DC lesion ( $n=6$ animals/ group) (Smolen et al., 1983; Mori et al., 1997; Kwon et al., 2002; Hains et al., 2003; Sasaki et al., 2006). Serial coronal sections $(20 \mu \mathrm{m})$ were made through the M1 cortex, and every 10th section was saved and digitized spanning bregma -2.0 to 2.0 . Only cells that displayed prominent nuclear profiles were scored. The total number of FG-positive cell profiles was estimated by the following formula:

$$
N_{\text {total }}=\frac{(t \cdot f) \cdot \sum_{i=1}^{n} Q_{i}}{t},
$$

where $N_{\text {total }}$ is the total number of FG-positive cell profiles, section thickness $t=20 \mu \mathrm{m}, f=10, Q_{i}=$ counted cell profiles in the uniformly sampled disectors (crude number), and $n=10$ (number of equidistant sections used in the analysis). The calculated distance from one disector to the next was $200 \mu \mathrm{m}$. The number of cells in each of the 1st to $i$ th sampled sections was used to calculate the coefficient of error (Gundersen et al., 1988; Abusaad et al., 1999; Hains et al., 2003; Sasaki et al., 2006).

Statistics. Comparison against control group was performed using a one-way ANOVA with Tukey's test post hoc. Data management and statistical analyses were performed using SigmaStat (version 3.0.1a; Jandel Scientific) and Microsoft Office Excel (2003) and graphed as mean \pm SEM using SigmaPlot (version 8.02a). 

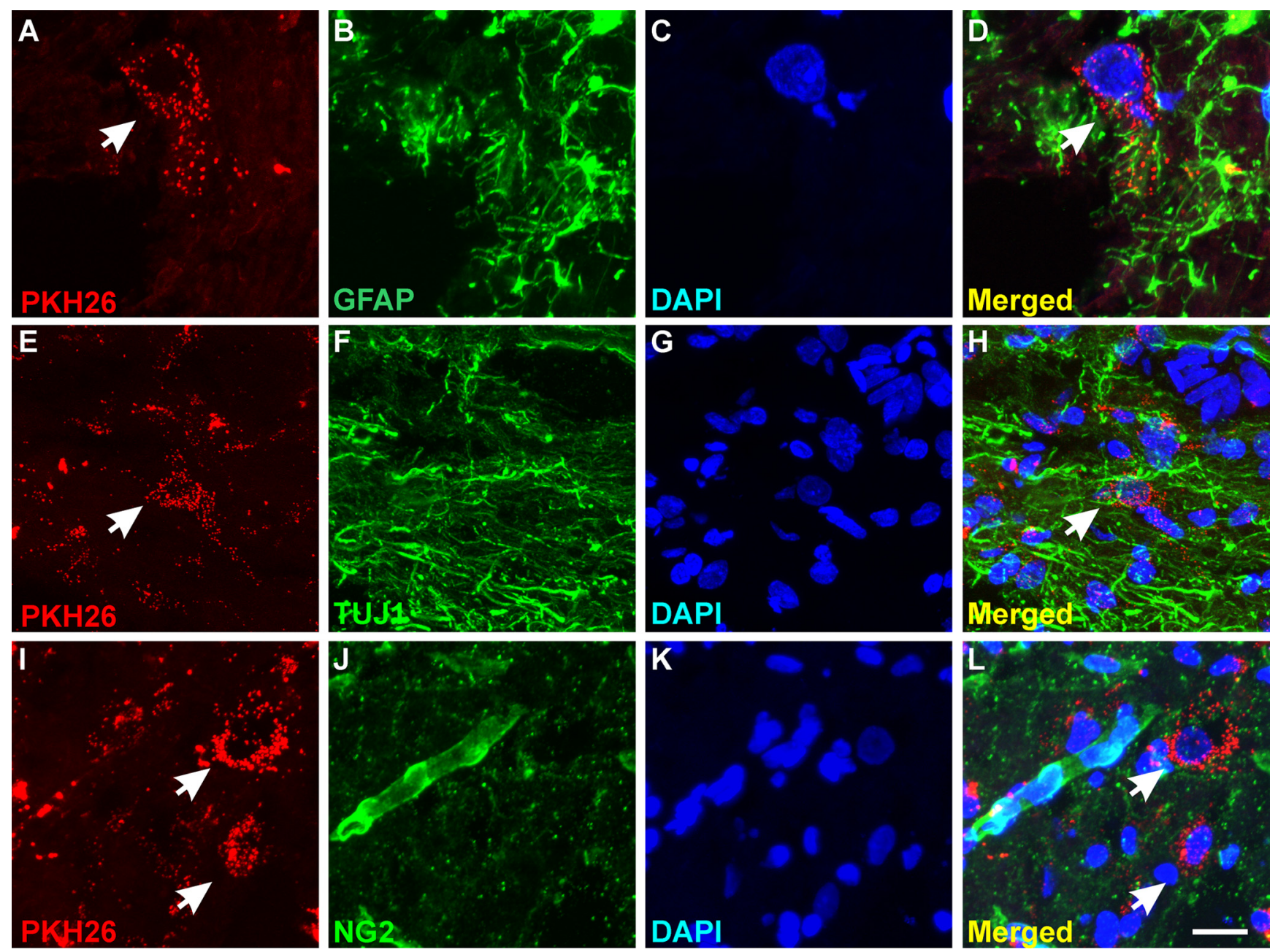

Figure 2. Immunohistochemical characterization of hMSCs in vivo. $\boldsymbol{A}-\mathbf{L}$, Transplanted hMSCs labeled with PKH26 could be identified by cytoplasmic localization of PKH26 (red; arrows) in the injured spinal cord site ( 5 weeks post-transplantation) with confocal microscopy. hMSCs did not express markers for astrocytes (GFAP; $\boldsymbol{A}-\boldsymbol{D})$, neurons (TUJ1; $\boldsymbol{E}-\boldsymbol{H}$ ), or oligodendrocytes (NG2; $\boldsymbol{I} \boldsymbol{L}$ ). PKH26 was largely localized in the perinuclear cytoplasmic compartment of the transplanted cells. Scale bar: (in $\boldsymbol{L}) \boldsymbol{A}-\boldsymbol{D}, 10 \mu \mathrm{m} ; \boldsymbol{E}-\boldsymbol{L}, 20 \mu \mathrm{m}$.

\section{Results}

Characteristics of primary hMSC and BDNF-hMSCs in vitro Primary hMSCs were cultured as plastic adherent cells to subconfluency, which took $\sim 1$ week (see Materials and Methods). Both hMSCs (Fig. $1 A$ ) and BDNF-hMSCs (Fig. $1 B$ ) were prelabeled with PKH26 to identify the transplanted cells in vivo. Superimposed Nomarski light microscopic and fluorescent images of PKH26-labeled cells nuclear stained with DAPI are shown in Figure 1, $A$ (hMSCs) and B (BDNF-hMSCs), respectively. PKH26 is a fluorescent lipophilic dye whose detection does not require immunostaining. PKH26 was localized in the cytoplasm of the characteristic flattened hMSCs and BDNFhMSCs in vitro (Fig. $1 A, B$ ). Flow cytometric analysis of the BDNF-hMSCs (Fig. 1C) was essentially identical to primary hMSCs (Fig. 1D). Both had CD $34^{-}, \mathrm{CD}_{4}{ }^{-}, \mathrm{SH} 2^{+}$(CD105), and $\mathrm{SH}_{3}{ }^{+}(\mathrm{CD} 73)$ cell surface phenotype. These data are in agreement with our previous work (Kobune et al., 2003; Kurozumi et al., 2004; Nomura et al., 2005).

Transplanted BDNF-hMSCs survive in the spinal cord transection site

The transplanted PKH26-labeled BDNF-hMSCs and hMSCs were easily identified within the lesion zone by their red fluorescence at both 1 and 5 weeks after transplantation. BDNF-
hMSC distribution in the injured SCI at 1 and 5 weeks are shown in supplemental Figure 1, available at www.jneurosci. org as supplemental material. At 1 week, the transplanted BDNF-hMSCs were confined largely to the lesion zone (supplemental Fig. 1A, available at www.jneurosci.org as supplemental material). At 5 weeks, the BDNF-hMSCs survived in the lesion zone, but a number of cells distributed outside of the lesion throughout the spinal cord and in the meningeal region (supplemental Fig. $1 \mathrm{~B}$, available at www.jneurosci.org as supplemental material). The distribution pattern was similar for hMSCs (data not shown). Cytoplasmic PKH26 localization in the perinuclear region of the hMSCs was also observed in vivo at 5 weeks after transplantation, indicating cell survival (supplemental Fig. $1 C, D$, available at www.jneurosci.org as supplemental material).

Immunostaining of spinal cord sections 5 weeks after transplantation of hMSCs and BDNF-hMSCs was performed for GFAP, TUJ1, and NG2. The transplanted cells were identified by the distribution of $\mathrm{PKH} 26$ in the cytoplasmic regions outside of the nucleus (Fig. $2 A, E, I$ ). There was no obvious colocalization of GFAP (Fig. $2 A-D$ ), TUJ1 (Fig. $2 E-H$ ), or NG2 (Fig. $2 I-L$ ) with PKH26-identified hMSCs. The hMSCs were embedded in areas rich in glial and neuronal processes but did not differentiate into glial or neuronal elements. 

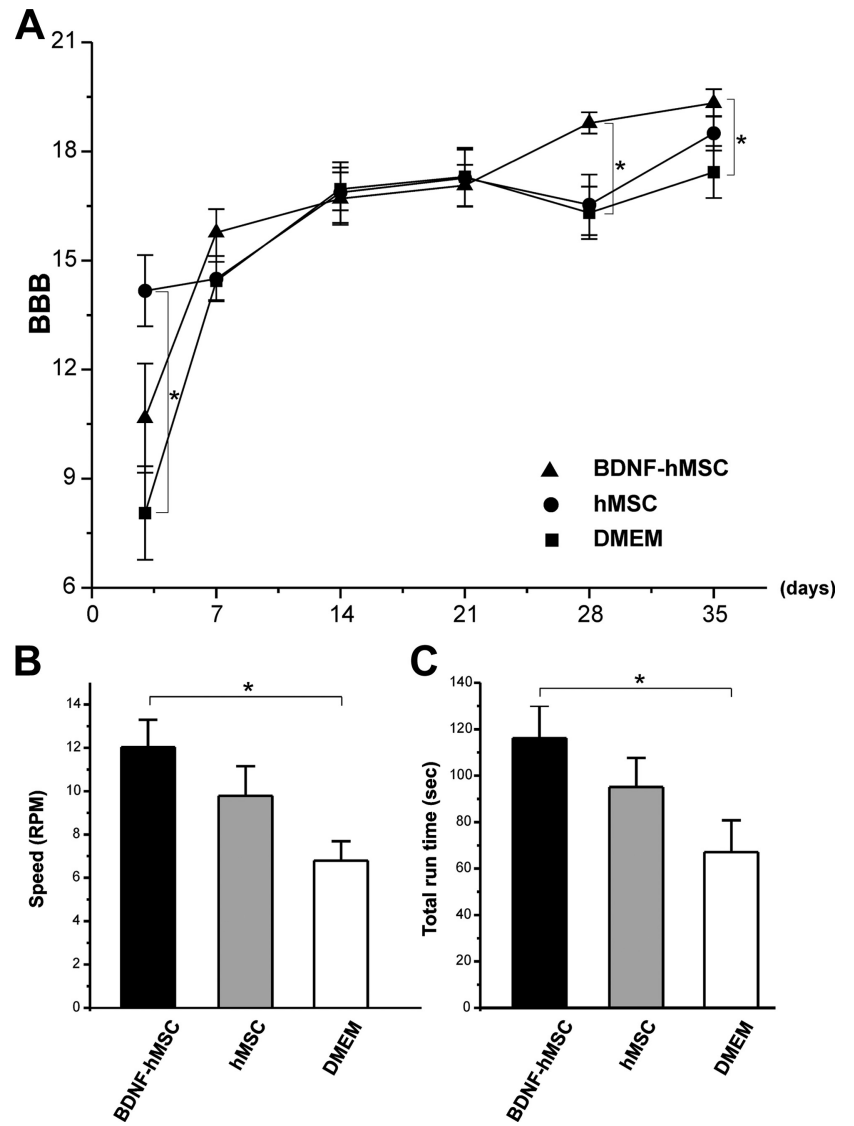

Figure 3. Behavioral analysis of locomotor function. $A, 0$ pen-field locomotor scores for BDNF-hMSC, hMSC, and DMEM (sham control) ( $n=16 /$ group) groups tested at day 3 and weekly until 5 weeks after transplantation. All animals showed a gradual improvement in hindlimb locomotor function during the 5 week recovery period. The BDNF-hMSC transplant group recovered to nearly 20 on the BBB score and displayed consistent weightbearing plantar stepping behavior. Statistical analysis indicated that the BBB scores at 4 and 5 weeks after injury in the BDNF-hMSC transplantation group $(18.8 \pm 0.29 ; 19.3 \pm$ $0.37)$ was significantly higher than those in the hMSC $(16.5 \pm 0.83 ; 18.5 \pm 0.48)$ and DMEM $(16.3 \pm 0.72 ; 17.4 \pm 0.71)$ groups. ${ }^{*} p<0.05 . B, C$, Rotarod testing demonstrated that all groups improved in their locomotor performance at 5 weeks after transplantation: rotarod at a rotation of $21.6 \pm 2.5 \mathrm{rpm}$ (maximal rpm scores) $(\boldsymbol{B})$ and for a duration of $242.7 \pm 25.9 \mathrm{~s}$ (total run time) $(\boldsymbol{C})$. In the DMEM group, rotation rates of $6.79 \pm 0.89 \mathrm{rpm}$ and duration of $67.11 \pm 13.65 \mathrm{~s}$ were observed. Rotation rates and duration were greater in the BDNF-hMSC group ( $12.0 \pm 1.26 \mathrm{rpm} ; 116.16 \pm 13.69 \mathrm{~s})$, but not in the hMSC group $(9.7 \pm 1.37 \mathrm{rpm} ; 95.2 \pm 12.5 \mathrm{~s})$, compared with the DMEM group $(p<0.05)$. Data are mean \pm SEM.

\section{Behavioral analysis of locomotor function}

Open-field locomotor scores for BDNF-hMSC, hMSC, and DMEM injection groups ( $n=16 /$ group) were tested 1 week before and $3 \mathrm{~d}$ and $1,2,3,4$, and 5 weeks after transplantation (Fig. $3 A)$. Intact animals $(n=6)$ scored 21 on the BBB test. All experimental animals exhibited a gradual improvement in hindlimb locomotor function during the 5 week recovery period. The BDNF-hMSC transplant group recovered to near 20 on the BBB score and displayed consistent weight-bearing plantar stepping behavior. Statistical analysis indicated that the BBB scores of BDNF-hMSC transplantation were higher than the hMSC and DMEM groups at 4 and 5 weeks after transplantation, respectively (Fig. 3A). Although a trend was observed, a difference between the hMSC and the DMEM groups at 5 weeks did not reach statistical significance ( $p=0.775$ with Tukey post hoc test).

Rotation rates (maximal rpm scores) and duration (total run time; seconds) were evaluated for the BDNF-hMSC, hMSC, and
DMEM control groups with rotarod testing at 5 weeks after transplantation (Fig. $3 B, C)$. Intact animals $(n=6)$ were able to stay on the rotarod at a rotation of $21.6 \pm 2.5 \mathrm{rpm}$, and for a duration of $242.7 \pm 25.9$ s. In the DMEM group, rotation rates of $6.79 \pm$ $0.89 \mathrm{rpm}$ and duration of $67.11 \pm 13.65 \mathrm{~s}$ were observed. Rotation rates and duration were greater in the BDNF-hMSC group $(12.0 \pm 1.26 \mathrm{rpm} ; 116.16 \pm 13.69 \mathrm{~s})$, but not in the hMSC group $(9.7 \pm 1.37 \mathrm{rpm}$; $95.2 \pm 12.5 \mathrm{~s})$, compared with the DMEM group $(p<0.05)$. As with the BBB test, a trend in the hMSC group was observed. Error bars represent mean \pm SEM.

\section{BDNF-hMSC and hMSC transplants promotes sprouting of CST fibers}

Image analysis on tissue with PKC- $\gamma$ immunostaining was performed to identify CST axons using similar methods as described previously (Barritt et al., 2006). Three bins were superimposed over the dorsal funiculus from coronal tissue sections sampled rostral and caudal to the SCI site. Levels of PKC- $\gamma$-immunopositive fibers were compared across the three experimental groups (Fig. $4 M, N$ ). In the DMEM (sham control) group, PKC- $\gamma$-immunopositive reactivity rostral to the lesion revealed dorsal CST fibers in the ventral portion of the dorsal funiculus (Fig. $4 A, B$ ) and small-diameter interneurons in the superficial dorsal horn (Fig. $4 A$ ). This pattern of PKC- $\gamma$ immunostaining was also consistent for tissue sections examined from animals within the BDNF-hMSC (Fig. 4I,J) and hMSC (Fig. 4E,F) groups. Five weeks after BDNF-hMSC transplantation, more PKC- $\gamma$-positive CST fibers appeared to sprout superficially into the intermediate region of the rostral dorsal funiculus (Fig. 4I,J,M) compared with the DMEM group. Compared with the DMEM group, the hMSC group also had increased PKC- $\gamma$ immunoreactivity in the ventral region. Image analysis of $\mathrm{PKC}-\gamma$ immunostaining in caudal spinal cord tissue sections located below the injury site demonstrated more dramatic effects of the transplant groups on CST sprouting (Fig. 4D, H,L). Comparison across experimental groups in the ventral region showed significantly more PKC- $\gamma$ fibers in the BDNF-hMSC transplant group (Fig. $4 K, L, N)$ compared with the DMEM group (Fig. $4 C, D$ ). In addition, more CST fibers were found in this ventral region with BDNF-hMSC transplants than with the hMSC group (Fig. $4 G, H, N$ ). More PKC- $\gamma$-immunopositive CST fibers sprouted into the dorsal region bin in the BDNF-hMSC group compared with both the hMSC and the DMEM groups. Error bars represent mean \pm SEM.

\section{Raphespinal fiber growth after BDNF-hMSC transplantation after SCI}

5-HT fiber growth was increased after BDNF-hMSC transplantation after SCI. Transverse sections $11-15 \mathrm{~mm}$ rostral to the lesion center of spinal cord stained with anti-serotonin antibodies from the DMEM (Fig. 5A), hMSC (Fig. 5B), and BDNF-hMSC (Fig. $5 C$ ) groups showed similar numbers of serotonergic fibers in the ventral horn (Fig. 5G). Transverse sections of spinal cord 11-15 mm caudal to the lesion center showed a significantly greater 5-HT fiber immunoreactivity of serotonergic fibers in the ventral horn of BDNF-hMSC (Fig. $5 F$ ) group compared with the DMEM group (Fig. 5D). Quantification of the optical density of the 5-HT immunoreactivity of serotonergic fiber in the ventral horn rostral and caudal to the SCI lesion indicates that there is a significant increase of serotonergic fibers in the ventral horn caudal (Fig. $5 H$ ) to the lesion in the BDNF-hMSC group, compared 

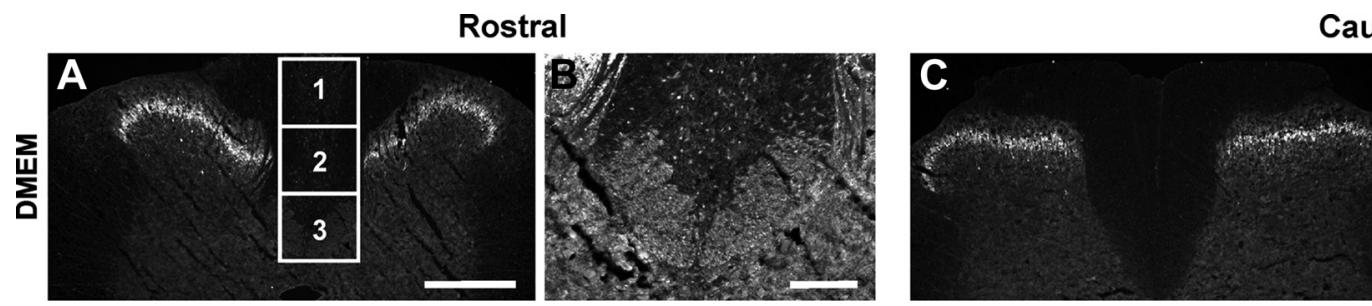

Caudal
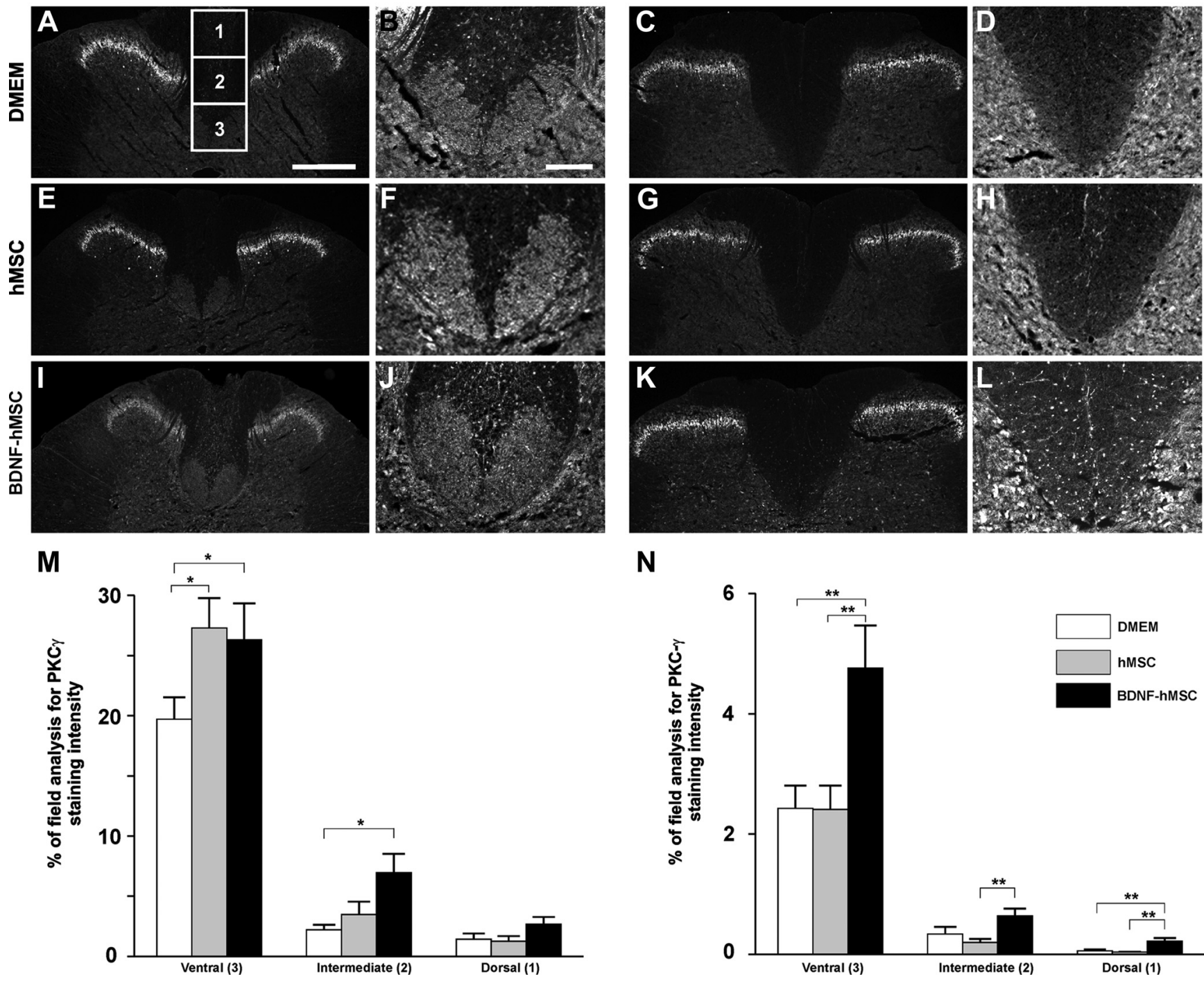

$\mathbf{N}$

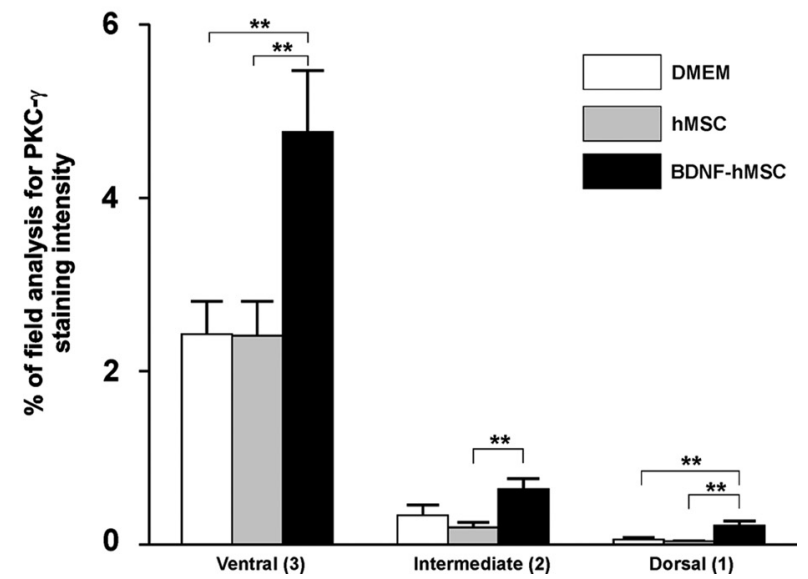

Figure 4. $\quad \boldsymbol{A}-\boldsymbol{L}$, PKC- $\gamma$ staining reveals descending CST fibers in the dorsal column of spinal cord tissue. DMEM $(\boldsymbol{A}-\boldsymbol{D})$, hMSC $(\boldsymbol{E}-\boldsymbol{H})$, and BDNF-hMSC (I-L) rostral to the injury center $(\boldsymbol{A}, \boldsymbol{B}, \boldsymbol{E}, \boldsymbol{F}, \boldsymbol{I}, \boldsymbol{J})$ and caudal to the injury center $(\boldsymbol{C}, \boldsymbol{D}, \boldsymbol{G}, \boldsymbol{H}, \boldsymbol{K}, \boldsymbol{L}) . \boldsymbol{M}, \boldsymbol{N}$, Percentages obtained by field analysis for PKC $\gamma \boldsymbol{\gamma}$ staining intensity for three regions aligned in the dorsoventral axis. Five weeks after BDNF-hMSC transplantation, more PKC- $\gamma$-positive CST fibers appeared to sprout superficially into the intermediate region of the rostral dorsal funiculus $(\boldsymbol{I}, \boldsymbol{J}, \boldsymbol{M})$ compared with the DMEM group $(6.95 \pm 1.7$ vs $2.21 \pm 1.0 \%$ of field; $p<0.05)$. Compared with the DMEM group, the hMSC group also had increased PKC- $\gamma$ immunoreactivity in the ventral region ( $27.3 \pm 2.5$ vs $19.7 \pm 1.8 \%$ of field, $p<0.05$ ). Image analysis of PKC- $\gamma$ immunostaining in caudal spinal cord tissue sections located below the injury site demonstrated more dramatic effects of the transplant groups on CST sprouting $(\boldsymbol{D}, \boldsymbol{H}, \boldsymbol{L})$. Comparison across experimental groups in the ventral region showed significantly more PKC- $\gamma$ fibers in the BDNF-hMSC transplant group $(\boldsymbol{K}, \boldsymbol{L}, \boldsymbol{N})$ compared with the DMEM group $(\boldsymbol{C}, \boldsymbol{D})(4.7 \pm 1.0$ vs $2.5 \pm 0.9 \%$ of field, $p<0.01)$. In addition, more $C S T$ fibers were found in this ventral region with BDNF-hMSC transplants than with the hMSC group $(\boldsymbol{G}, \boldsymbol{H}, \boldsymbol{N})(4.7 \pm 1.0$ vs $2.4 \pm 1.0 \%$ of field, $p<0.01)$. More PKC- $\gamma$-immunopositive CST fibers sprouted into the dorsal region bin in the BDNF-hMSC group compared with both the hMSC $(0.27 \pm 3.8$ vs $0.08 \pm 1.0 \%$ of field, $p<0.05)$ and the DMEM $(0.27 \pm 1.1$ vs $0.11 \pm 1.0 \%$ of field, $p<0.01$ ) groups. Data are mean \pm SEM. Scale bars: (in $A), A, C, E, G, I, K, 500 \mu \mathrm{m}$; (in $B), B, D, F, H, J, L, 100 \mu \mathrm{m}$. Boxed areas in $\boldsymbol{A}$ denote regions selected for quantification. ${ }^{*} p<0.05,{ }^{* *} p<0.01$.

with the DMEM group, but no statistical difference rostral to the lesion (Fig. 5I).

Transplantation reduces corticospinal neuronal loss

Bilateral transection of the dorsal CST and FG injection at T9 results in robust retrograde labeling of the cell bodies of these axons within layer $\mathrm{V}$ of the primary motor cortex (M1) (Fig. 6); which spans from approximately bregma 1.6 through -1.6 (Hains et al., 2003; Sasaki et al., 2006). In the coronal plane, the anatomical location of labeled cells was within a region lateral to the midline longitudinal fissure and medial to the forelimb region of the primary sensory cortex (S1) and within cortical layer $\mathrm{V}$. In the sagittal plane, the anterior distribution of FG-labeled cells extended to the rostral margin of the anterior commissure and extended caudally to the posterior margin of the optic chiasm. Retrogradely labeled cells displayed pyramidal-shaped somata, which give rise to a singular apical dendrite and smaller basal dendrites. In the rostrocaudal dimension, the density of backfilled CST neurons was highest at approximately bregma -0.3 . At 5 weeks after SCI, quantification of the number of FGpositive neurons was significantly higher in both the BDNFhMSC and hMSC groups $(p<0.01)$ compared with the DMEM group, but the BDNF-hMSC group was greater. Figure 6, $A$ to $C$, shows corresponding sections through bregma -0.3 of the three experimental groups. Stereological analysis indicates that the estimated total neuronal counts among the DMEM, hMSC, and 
BDNF-hMSC groups are $675 \pm 44.2$, $798 \pm 29.3$, and $909 \pm 34.8$, respectively, at 5 weeks (Fig. 6D).

\section{Discussion}

Bone marrow-derived cells (mononuclear or marrow stromal cells) from experimental animal sources transplanted into SCI models have demonstrated variable degrees of functional improvement (Chopp et al., 2000; Hofstetter et al., 2002; Ankeny et al., 2004; Kamada et al., 2005; Cízková et al., 2006; Himes et al., 2006: Shichinohe et al., 2008; Someya et al., 2008; Zurita et al., 2008). In the present study, we prepared highly purified and identified MSCs (Kobune et al., 2003) from human bone marrow to study their impact on SCI. The hMSCs increased axonal sprouting and increased the number of surviving M1 cortical neurons but did not lead to improved functional outcome with our testing paradigms, although a trend was observed. Several studies have demonstrated that BDNF delivery is protective to injured CST neurons and can improve functional outcome after SCI (Jakeman et al., 1998; Namiki et al., 2000; Kim and Jahng, 2004; Kwon et al., 2007). We previously observed an increase in BDNF levels in the SCI transplantation zone after olfactory ensheathing cell transplantation and an increased survival of M1 CST neurons and improved functional outcome, suggesting a contribution of BDNF (Sasaki et al., 2006). Moreover, genetically modified hMSCs that express BDNF have additive neuroprotective effects and reduce lesion volume in a cerebral infarction model compared with hMSCs alone (Kurozumi et al., 2004; Nomura et al., 2005). Therefore, we transplanted BDNF-hMSCs into an SCI model to determine whether these cells would enhance functional recovery over hMSCs alone because of the additive effect of BDNF delivery in this study. Transplantation of BDNF-hMSCs increased axonal sprouting and M1 cortical neuronal survival and led to a statistically significant improvement in functional outcome.

Thus, the cellular delivery of BDNF can positively impact functional outcome in SCI. The comparison of hMSCs alone and BDNF-hMSCs provides more direct evidence for the role of BDNF in enhancing this cell therapy approach for experimental SCI.

Both transplanted hMSCs and BDNFhMSCs distributed in the lesion site at 1 week and survived in the spinal cord for the 5 week study period, suggesting that the difference in functional outcome be-
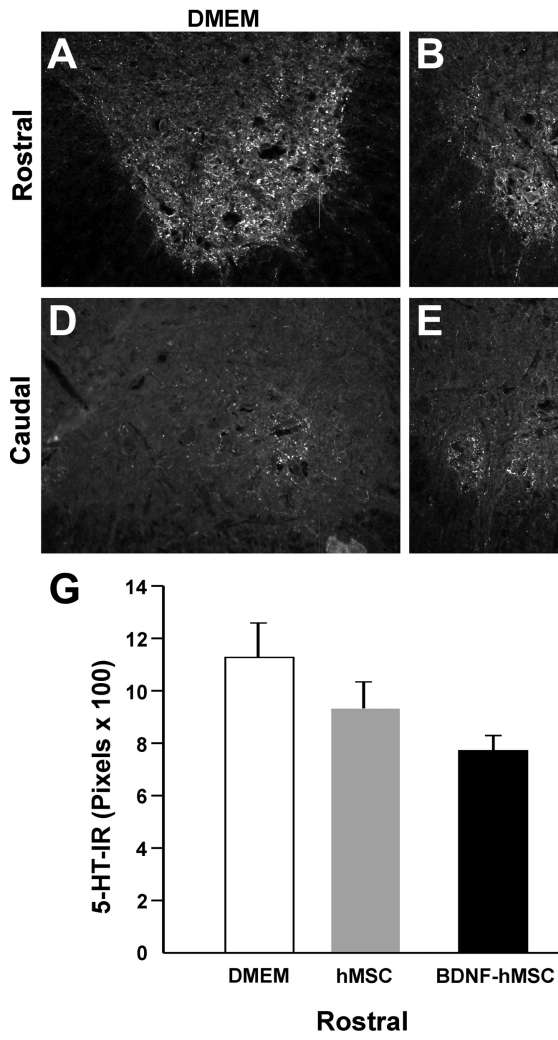

hMSC
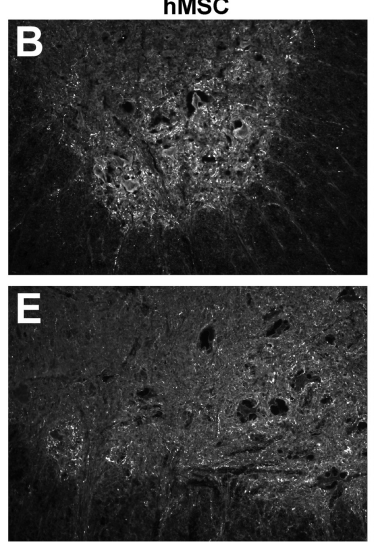

$H$
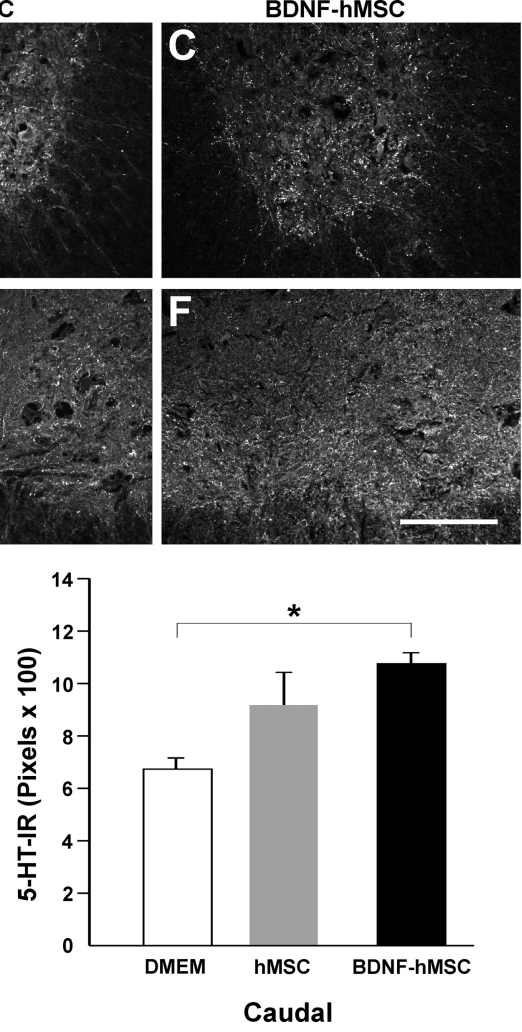

Figure 5. 5-HT fiber growth after BDNF-hMSC transplantation after SCI. $\boldsymbol{A}-\boldsymbol{F}$, Coronal sections of spinal cord rostral to the lesion center stained with anti-serotonin antibodies show similar numbers of serotonergic fibers in the ventral horn for DMEM $(\boldsymbol{A})$, hMSC $(\boldsymbol{B})$, and BDNF-hMSC $(\boldsymbol{C})$ groups. Coronal sections caudal to the lesion center show a significantly greater number of serotonergic fibers in the ventral horn of BDNF-hMSC group $(\boldsymbol{F})$ compared with other groups $(\boldsymbol{D}, \boldsymbol{E})$. $\boldsymbol{G}, \boldsymbol{H}$, Quantification of the optical density of the 5 -HT immunoreactivity of serotonergic fiber in the ventral horn rostral and caudal to the $\mathrm{SCl}$ lesion indicate that there is a significant increase of serotonergic fibers in the ventral horn caudal $(\boldsymbol{H})$ to the lesion in the BDNF-hMSC group (10.76 \pm 0.60 vs $6.73 \pm 0.49$, pixels $\times 100 ; p<0.05)$, compared with the DMEM group, but no statistical difference rostral to the lesion $(\boldsymbol{G})$. Data are mean \pm SEM. ${ }^{*} p<0.05$. Scale bar: (in $\boldsymbol{F}$ ) $\boldsymbol{A}-\boldsymbol{F}$, $200 \mu \mathrm{m}$.

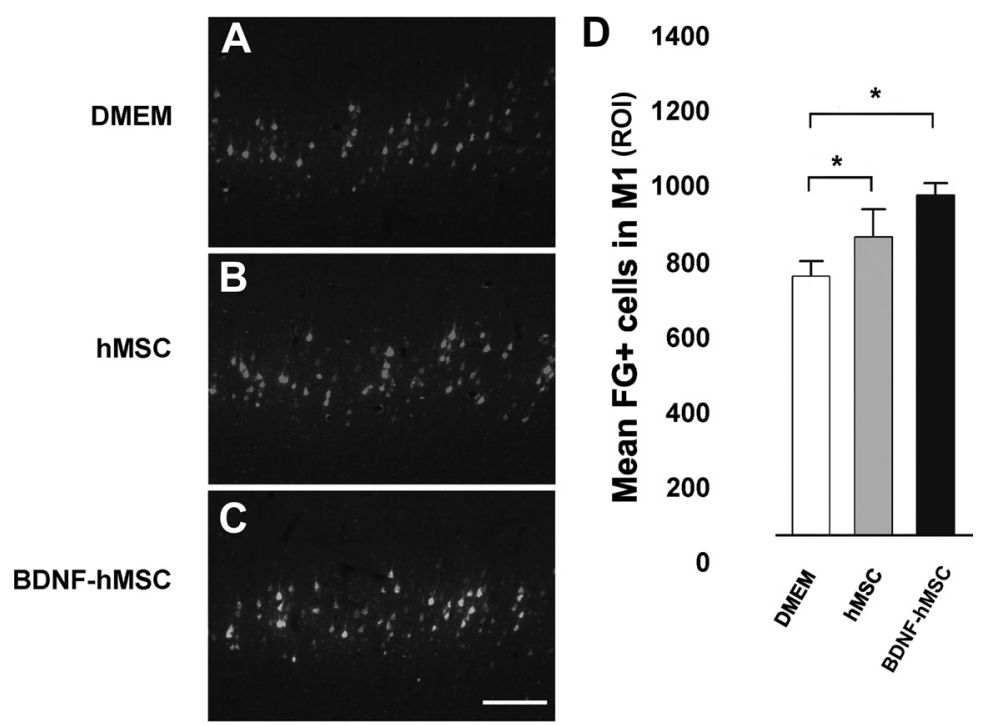

Figure 6. Density of FG-positive corticospinal neurons. A-C, The density of retrogradely labeled FG-positive corticospinal neurons at bregma -0.3 at 5 weeks after $S C$ is greater in hMSC $(\boldsymbol{B})$ and BDNF-hMSC $(\boldsymbol{C})$ groups compared with the DMEM group $(\boldsymbol{A})$. D, Quantification of the number of FG-positive neurons was significantly higher in both the BDNFhMSC and hMSC groups $\left({ }^{*} p<0.05\right)$, but the BDNF-hMSC group was greater. Data are mean \pm SEM. Scale bar: (in $\left.\boldsymbol{C}\right) \boldsymbol{A}-\boldsymbol{C}$, $125 \mu \mathrm{m}$. 
tween the two groups was not the result of a difference in cell survival. Although only a trend in improvement in functional outcome was observed with hMSCs alone, the effects of hMSCs alone on increasing cortical neuronal survival and increasing sprouting should not be discounted. MSCs secrete a variety of bioactive substances, such as neurotrophins (including BDNF), interleukins, macrophage colony-stimulating factor, Flt-3 ligand, and stem cell factors, that could contribute to these changes (Eaves et al., 1991; Majumdar et al., 1998).

PKC- $\gamma$ colocalizes with CST fibers and small-diameter neurons located in the substantia gelatinosa of the adult rat spinal cord (Akinori, 1998). Because of its expression pattern in the spinal cord motor system, specifically in rodent species, PKC- $\gamma$ has been shown to be useful for investigating CST sprouting and plasticity in SCI models (Bradbury et al., 2002; Barritt et al., 2006; Cafferty and Strittmatter, 2006). Transplantation of hMSCs and BDNF-hMSCs promoted sprouting of PKC- $\gamma$-immunopositive CST fibers both above and below the SCI site. hMSC and BDNFhMSC transplantation resulted in CST fiber sprouting into more superficial regions (ventral) of the dorsal funiculus in rostral tissue above the injury site. In addition, the BDNFhMSC group sprouted into the intermediate dorsal funicular region rostral to the lesion, but the hMSC group did not. Therefore, the increased CST fiber sprouting in the BDNFhMSC group in the rostral dorsal funiculus tissue regions suggests that BDNF induces increased plasticity within the spinal cord. This growth pattern may be explained by either of two ways: first, by the extrinsic chemoattractive properties of BDNF (Nakahara et al., 1996; Ebadi et al., 1997; Bamber et al., 2001), or second, by the intrinsic growth-promoting stimulus that BDNF can provide to subclasses of injured axons (Filbin, 2003; Zhou and Shine, 2003). As the impact of BDNF-hMSC has a longitudinal effect, providing impetus to enhance growth bidirectional from the injury site, it may be interesting for future investigation to determine whether BDNF-hMSCs can affect other axonal types (i.e., ascending sensory afferents) after SCI. Interestingly, only the BDNF-hMSC group promoted CST sprouting into the dorsal funiculus caudal to the injury site compared with both the hMSC and DMEM groups. Thus, these results together support the importance of BDNF in reported functional improvement and that BDNF can be delivered by a cell therapy approach.

It is possible that the rostral CST axonal sprouting induced by BDNF-hMSC may contribute to recovery through an enhancement of polysynaptic connections to the caudal spinal cord. Bareyre et al. (2004) demonstrated that the course of endogenous functional recovery is associated with sprouting of CST axons above the lesion that synapse on long propriospinal neurons. In turn, the propriospinal neurons, which project below the lesion, sprout and provide greater synaptic drive to motor neurons below the lesion.

Raphespinal fibers were not completely severed by the dorsolateral transection SCI model. In the BDNF-hMSC group, increased 5-HT fibers were detected in the ventral horns of spinal cord. Several studies suggest the importance of raphespinal inputs to spinal motor neurons in motor performance (Morrison and Gebber, 1985; Wang et al., 2006). Moreover, a number of treatments including application of Nogo inhibitors results in 5 -HT axonal sprouting and improved functional outcome in rodent SCI models (Wang et al., 2006). The increased 5-HT fiber sprouting we observed after BDNF-hMSC transplantation may at least partially account for the improvement in functional outcome.
Several groups have reported that CST neurons of M1 cortex undergo atrophy (McBride et al., 1989; Tang et al., 2004; Carter et al., 2008) after SCI, as well as dynamic changes in the density and morphology of dendritic spines of M1 neurons in rat (Kim et al., 2006). In mice, Carter et al. (2008) observed significant atrophy of CST neuron somata after thoracic SCI using a yellow fluorescent protein (YFP-H) transgenic mouse model. In humans, structural abnormalities with reduced tissue volume after SCI by MRI approaches have been demonstrated (Wrigley et al., 2009). Cell loss in M1 cortex after SCI has also been reported (Hains et al., 2003; Lee et al., 2004; Klapka et al., 2005; Sasaki et al., 2006). Klapka et al. (2005) reported functional recovery and increased cell numbers on pyramidal motor neurons in M1 cortex following scar-suppressing treatment with local application of an iron chelator (BPY-DCA) following SCI in rats. In the present study, hMSC and BDNF-hMSC transplants demonstrated the preservation of the number of CST neurons in M1 compared with the sham control (DMEM group). Rescue of CST neurons by hMSC and BDNF-hMSCs could provide for a greater upper motor neuronal pool that through sprouting above the lesion might enhance new intraspinal circuits to regions below the lesion, e.g., propriospinal (Bareyre et al., 2004). It is important to note that Lu et al. (2005) did not see improved functional outcome after transplantation of BDNF-hypersecreting rat MSCs in a rodent SCI model. One difference between their study and ours was that they injured the spinal cord at C3 and studied forelimb function, which requires more precise targeting of regenerated axons to the motor neurons than for hindlimb function. Our lesion was at T9. It is possible that the improvement we report in hindlimb function with BDNF-hMSC was because spinal cord target sites for hindlimb function may not need as extensive and precise reinnervation as would targets for forelimb function.

In summary, the transplantation of hMSCs expressing BDNF promotes functional recovery, sprouting of CST and raphespinal fibers, and protection of CST neurons after SCI. Thus, cellular delivery of BDNF secreted by hMSCs may have a therapeutic effect following some forms of acute SCI.

\section{References}

Abusaad I, MacKay D, Zhao J, Stanford P, Collier DA, Everall IP (1999) Stereological estimation of the total number of neurons in the murine hippocampus using the optical disector. J Comp Neurol 408:560-566.

Akinori M (1998) Subspecies of protein kinase C in the rat spinal cord. Prog Neurobiol 54:499-530.

Ankeny DP, McTigue DM, Jakeman LB (2004) Bone marrow transplants provide tissue protection and directional guidance for axons after contusive spinal cord injury in rats. Exp Neurol 90:17-31.

Azizi SA, Stokes D, Augelli BJ, DiGirolamo C, Prockop DJ (1998) Engraftment and migration of human bone marrow stromal cells implanted in the brains of albino rats-similarities to astrocyte grafts. Proc Natl Acad Sci U S A 95:3908-3913.

Bai L, Lennon DP, Eaton V, Maier K, Caplan AI, Miller SD, Miller RH (2009) Human bone marrow-derived mesenchymal stem cells induce Th2polarized immune response and promote endogenous repair in animal models of multiple sclerosis. Glia. Advance online publication. Retrieved 29 October, 2009. doi:10.1002/glia.20841.

Bamber NI, Li H, Lu X, Oudega M, Aebischer P, Xu XM (2001) Neurotrophins BDNF and NT-3 promote axonal re-entry into the distal host spinal cord through Schwann cell-seeded mini-channels. Eur J Neurosci 13:257-268.

Bareyre FM, Kerschensteiner M, Raineteau O, Mettenleiter TC, Weinmann O, Schwab ME (2004) The injured spinal cord spontaneously forms a new intraspinal circuit in adult rats. Nat Neurosci 7:269-277.

Barritt AW, Davies M, Marchand F, Hartley R, Grist J, Yip P, McMahon SB, Bradbury EJ (2006) Chondroitinase ABC promotes sprouting of intact and injured spinal systems after spinal cord injury. J Neurosci 26:10856-10867. 
Basso DM, Beattie MS, Bresnahan JC (1995) A sensitive and reliable locomotor rating scale for open field testing in rats. J Neurotrama 12:1-21.

Bradbury EJ, Moon LD, Popat RJ, King VR, Bennett GS, Patel PN, Fawcett JW, McMahon SB (2002) Chondroitinase ABC promotes functional recovery after spinal cord injury. Nature 416:636-640.

Brazelton TR, Rossi FM, Keshet GI, Blau HM (2000) From marrow to brain: expression of neuronal phenotypes in adult mice. Science 290:1775-1779.

Cafferty WB, Strittmatter SM (2006) The Nogo-Nogo receptor pathway limits a spectrum of adult CNS axonal growth. J Neurosci 26:1224212250.

Carter LM, Starkey ML, Akrimi SF, Davies M, McMahon SB, Bradbury EJ (2008) The yellow fluorescent protein (YFP-H) mouse reveals neuroprotection as a novel mechanism underlying chondroitinase $\mathrm{ABC}$-mediated repair after spinal cord injury. J Neurosci 28:14107-14120.

Chen X, Li Y, Wang L, Katakowski M, Zhang L, Chen J, Xu Y, Gautam SC, Chopp M (2002) Ischemic rat brain extracts induce human marrow stromal cell growth factor production. Neuropathology 22:275-279.

Chopp M, Zhang XH, Li Y, Wang L, Chen J, Lu D, Lu M, Rosenblum M (2000) Spinal cord injury in rat: treatment with bone marrow stromal cell transplantation. Neuroreport 11:3001-3005.

Cízková D, Rosocha J, Vanický I, Jergová S, Cízek M (2006) Transplants of human mesenchymal stem cells improve functional recovery after spinal cord injury in the rat. Cell Mol Neurobiol 26:1167-1180.

Eaves CJ, Cashman JD, Kay RJ, Dougherty GJ, Otsuka T, Gaboury LA, Hogge DE, Lansdorp PM, Eaves AC, Humphries RK (1991) Mechanisms that regulate the cell cycle status of very primitive hematopoietic cells in longterm human marrow cultures. II. Analysis of positive and negative regulators produced by stromal cells within the adherent layer. Blood 78:110-117.

Ebadi M, Bashir RM, Heidrick ML, Hamada FM, Refaey HE, Hamed A, Helal G, Baxi MD, Cerutis DR, Lassi NK (1997) Neurotrophins and their receptors in nerve injury and repair. Neurochem Int 30:347-374.

Filbin MT (2003) Myelin-associated inhibitors of axonal regeneration in the adult mammalian CNS. Nat Rev Neurosci 4:703-713.

Friedenstein AJ (1976) Precursor cells of mechanocytes. Int Rev Cytol 47:327-359.

Gundersen HJ, Bagger P, Bendtsen TF, Evans SM, Korbo L, Marcussen N, Møller A, Nielsen K, Nyengaard JR, Pakkenberg B, Sorensen FB, Vesterby A, West MJ (1988) The new stereological tools: disector, fractionator, nucleator and point sampled intercepts and their use in pathological research and diagnosis. APMIS 96:857-881.

Hains BC, Black JA, Waxman SG (2003) Primary cortical motor neurons undergo apoptosis following axotomizing spinal cord injury. J Comp Neurol 462:328-341.

Hamano K, Li TS, Kobayashi T, Kobayashi S, Matsuzaki M, Esato K (2000) Angiogenesis induced by the implantation of self-bone marrow cells: a new material for therapeutic angiogenesis. Cell Transplant 9:439-443.

Hiebert GW, Khodarahmi K, McGraw J, Steeves JD, Tetzlaff W (2002) Brain-derived neurotrophic factor applied to the motor cortex promotes sprouting of corticospinal tract fibers but not regeneration into a peripheral nerve transplant. J Neurosci Res 69:160-168.

Himes BT, Neuhuber B, Coleman C, Kushner R, Swanger SA, Kopen GC, Wagner J, Shumsky JS, Fischer I (2006) Recovery of function following grafting of human bone marrow-derived stromal cells into the injured spinal cord. Neurorehabil Neural Repair 20:278-296.

Hofstetter CP, Schwarz EJ, Hess D, Widenfalk J, El Manira A, Prockop DJ, Olson L (2002) Marrow stromal cells form guiding strands in the injured spinal cord and promote recovery. Proc Natl Acad Sci U S A 99:2199-2204.

Honma T, Honmou O, Iihoshi S, Harada K, Houkin K, Hamada H, Kocsis JD (2006) Intravenous infusion of immortalized human mesenchymal stem cells protects against injury in a cerebral ischemia model in adult rat. Exp Neurol 199:56-66.

Iihoshi S, Honmou O, Houkin K, Hashi K, Kocsis JD (2004) A therapeutic window for intravenous administration of autologous bone marrow after cerebral ischemia in adult rats. Brain Res 1007:1-9.

Jakeman LB, Wei P, Guan Z, Stokes BT (1998) Brain-derived neurotrophic factor stimulates hindlimb stepping and sprouting of cholinergic fibers after spinal cord injury. Exp Neurol 154:170-184.

Kamada T, Koda M, Dezawa M, Yoshinaga K, Hashimoto M, Koshizuka S, Nishio Y, Moriya H, Yamazaki M (2005) Transplantation of bone marrow stromal cell-derived Schwann cells promotes axonal regeneration and functional recovery after complete transection of adult rat spinal cord. J Neuropathol Exp Neurol 64:37-45.

Kim BG, Dai HN, McAtee M, Vicini S, Bregman BS (2006) Remodeling of synaptic structures in the motor cortex following spinal cord injury. Exp Neurol 198:401-415.

Kim DH, Jahng TA (2004) Continuous brain-derived neurotrophic factor (BDNF) infusion after methylprednisolone treatment in severe spinal cord injury. J Korean Med Sci 19:113-122.

Klapka N, Hermanns S, Straten G, Masanneck C, Duis S, Hamers FP, Müller D, Zuschratter W, Müller HW (2005) Suppression of fibrous scarring in spinal cord injury of rat promotes long-distance regeneration of corticospinal tract axons, rescue of primary motoneurons in somatosensory cortex and significant functional recovery. Eur J Neurosci 22:3047-3058.

Kobune M, Kawano Y, Ito Y, Chiba H, Nakamura K, Tsuda H, Sasaki K, Dehari H, Uchida H, Honmou O, Takahashi S, Bizen A, Takimoto R, Matsunaga T, Kato J, Kato K, Houkin K, Niitsu Y, Hamada H (2003) Telomerized human multipotent mesenchymal cells can differentiate into hematopoietic and cobblestone area-supporting cells. Exp Hematol 31:715-722.

Koda M, Kamada T, Hashimoto M, Murakami M, Shirasawa H, Sakao S, Ino H, Yoshinaga K, Koshizuka S, Moriya H, Yamazaki M (2007) Adenovirus vector-mediated ex vivo gene transfer of brain-derived neurotrophic factor to bone marrow stromal cells promotes axonal regeneration after transplantation in completely transected adult rat spinal cord. Eur Spine J 16:2206-2214

Kopen GC, Prockop DJ, Phinney DG (1999) Marrow stromal cells migrate throughout forebrain and cerebellum, and they differentiate into astrocytes after injection into neonatal mouse brains. Proc Natl Acad Sci U S A 96:10711-10716.

Krause DS, Theise ND, Collector MI, Henegariu O, Hwang S, Gardner R, Neutzel S, Sharkis SJ (2001) Multi-organ, multi-lineage engraftment by a single bone marrow-derived stem cell. Cell 105:369-377.

Kurozumi K, Nakamura K, Tamiya T, Kawano Y, Kobune M, Hirai S, Uchida H, Sasaki K, Ito Y, Kato K, Honmou O, Houkin K, Date I, Hamada H (2004) BDNF gene-modified mesenchymal stem cells promote functional recovery and reduce infarct size in the rat middle cerebral artery occlusion model. Mol Ther 9:189-197.

Kwon BK, Liu J, Messerer C, Kobayashi NR, McGraw J, Oschipok L, Tetzlaff W (2002) Survival and regeneration of rubrospinal neurons 1 year after spinal cord injury. Proc Natl Acad Sci U S A 99:3246-3251.

Kwon BK, Liu J, Lam C, Plunet W, Oschipok LW, Hauswirth W, Di Polo A, Blesch A, Tetzlaff W (2007) Brain-derived neurotrophic factor gene transfer with adeno-associated viral and lentiviral vectors prevents rubrospinal neuronal atrophy and stimulates regeneration-associated gene expression after acute cervical spinal cord injury. Spine 32:1164-1173.

Lee BH, Lee KH, Kim UJ, Yoon DH, Sohn JH, Choi SS, Yi IG, Park YG (2004) Injury in the spinal cord may produce cell death in the brain. Brain Res 1020:37-44.

Lee JK, Johnson CS, Wrathall JR (2007) Up-regulation of 5-HT2 receptors is involved in the increased H-reflex amplitude after contusive spinal cord injury. Exp Neurol 203:502-511.

Li Y, Chen J, Chen XG, Wang L, Gautam SC, Xu YX, Katakowski M, Zhang LJ, Lu M, Janakiraman N, Chopp M (2002) Human marrow stromal cell therapy for stroke in rat: neurotrophins and functional recovery. Neurology 59:514-523.

Liu H, Honmou O, Harada K, Nakamura K, Houkin K, Hamada H, Kocsis JD (2006) Neuroprotection by PlGF gene-modified human mesenchymal stem cells after cerebral ischemia. Brain 129:2734-2745.

Lu P, Jones LL, Tuszynski MH (2005) BDNF-expressing marrow stromal cells support extensive axonal growth at sites of spinal cord injury. Exp Neurol 191:344-360.

Majumdar MK, Thiede MA, Mosca JD, Moorman M, Gerson SL (1998) Phenotypic and functional comparison of cultures of marrow-derived mesenchymal stem cells (MSCs) and stromal cells. J Cell Physiol 176:57-66.

McBride RL, Feringa ER, Garver MK, Williams JK Jr (1989) Prelabeled red nucleus and sensorimotor cortex neurons of the rat survive 10 and 20 weeks after spinal cord transection. J Neuropathol Exp Neurol 48:568-576.

Mori F, Himes BT, Kowada M, Murray M, Tessler A (1997) Fetal spinal cord transplants rescue some axotomized rubrospinal neurons from retrograde cell death in adult rats. Exp Neurol 143:45-60. 
Morrison SF, Gebber GL (1985) Axonal branching patterns and funicular trajectories of raphespinal sympathoinhibitory neurons. J Neurophysiol 53:759-772.

Nakahara Y, Gage FH, Tuszynski MH (1996) Grafts of fibroblasts genetically modified to secrete NGF, BDNF, NT-3, or basic FGF elicit differential responses in the adult spinal cord. Cell Transplant 5:191-204.

Namiki J, Kojima A, Tator CH (2000) Effect of brain-derived neurotrophic factor, nerve growth factor, and neurotrophin-3 on functional recovery and regeneration after spinal cord injury in adult rats. J Neurotrauma 17:1219-1231.

Nomura T, Honmou O, Harada K, Houkin K, Hamada H, Kocsis JD (2005) I.V. infusion of brain-derived neurotrophic factor gene-modified human mesenchymal stem cells protects against injury in a cerebral ischemia model in adult rat. Neuroscience 136:161-169.

Ohtaki H, Ylostalo JH, Foraker JE, Robinson AP, Reger RL, Shioda S, Prockop DJ (2008) Stem/progenitor cells from bone marrow decrease neuronal death in global ischemia by modulation of inflammatory/immune responses. Proc Natl Acad Sci U S A 105:14638-14643.

Onda T, Honmou O, Harada K, Houkin K, Hamada H, Kocsis JD (2008) Therapeutic benefits by human mesenchymal stem cells (hMSCs) and Ang-1 gene-modified hMSCs after cerebral ischemia. J Cereb Blood Flow Metab 28:329-340.

Parr AM, Tator CH, Keating A (2007) Bone marrow-derived mesenchymal stromal cells for the repair of central nervous system injury. Bone Marrow Transplant 40:609-619.

Pittenger MF, Mackay AM, Beck SC, Jaiswal RK, Douglas R, Mosca JD, Moorman MA, Simonetti DW, Craig S, Marshak DR (1999) Multilineage potential of adult human mesenchymal stem cells. Science 284:143-147.

Prockop DJ (1997) Marrow stromal cells as stem cells for nonhematopoietic tissues. Science 276:71-74

Sanchez-Ramos J, Song S, Cardozo-Pelaez F, Hazzi C, Stedeford T, Willing A, Freeman TB, Saporta S, Janssen W, Patel N, Cooper DR, Sanberg PR (2000) Adult bone marrow stromal cells differentiate into neural cells in vitro. Exp Neurol 164:247-256.

Sasaki M, Lankford KL, Zemedkun M, Kocsis JD (2004) Identified olfactory ensheathing cells transplanted into the transected dorsal funiculus bridge the lesion and form myelin. J Neurosci 24:8485-8493.

Sasaki M, Hains BC, Lankford KL, Waxman SG, Kocsis JD (2006) Protection of corticospinal tract neurons after dorsal spinal cord transection and engraftment of olfactory ensheathing cells. Glia 53:352-359.

Shen LH, Li Y, Chen J, Zhang J, Vanguri P, Borneman J, Chopp M (2006)
Intracarotid transplantation of bone marrow stromal cells increases axonmyelin remodeling after stroke. Neuroscience 137:393-399.

Shichinohe H, Kuroda S, Tsuji S, Yamaguchi S, Yano S, Lee JB, Kobayashi H, Kikuchi S, Hida K, Iwasaki Y (2008) Bone marrow stromal cells promote neurite extension in organotypic spinal cord slice: significance for cell transplantation therapy. Neurorehabil Neural Repair 22:447-457.

Smolen AJ, Wright LL, Cunningham TJ (1983) Neuron numbers in the superior cervical sympathetic ganglion of the rat: a critical comparison of methods for cell counting. J Neurocytol 12:739-750.

Someya Y, Koda M, Dezawa M, Kadota T, Hashimoto M, Kamada T, Nishio Y, Kadota R, Mannoji C, Miyashita T, Okawa A, Yoshinaga K, Yamazaki M (2008) Reduction of cystic cavity, promotion of axonal regeneration and sparing, and functional recovery with transplanted bone marrow stromal cell-derived Schwann cells after contusion injury to the adult rat spinal cord. J Neurosurg Spine 9:600-610.

Tan AM, Stamboulian S, Chang YW, Zhao P, Hains AB, Waxman SG, Hains BC (2008) Neuropathic pain memory is maintained by Racl-regulated dendritic spine remodeling after spinal cord injury. J Neurosci 28:1317313183.

Tang XQ, Wang Y, Huang ZH, Han JS, Wan Y (2004) Adenovirus-mediated delivery of GDNF ameliorates corticospinal neuronal atrophy and motor function deficits in rats with spinal cord injury. Neuroreport 15:425-429.

Vavrek R, Girgis J, Tetzlaff W, Hiebert GW, Fouad K (2006) BDNF promotes connections of corticospinal neurons onto spared descending interneurons in spinal cord injured rats. Brain 129:1534-1545.

Wang X, Baughman KW, Basso DM, Strittmatter SM (2006) Delayed Nogo receptor therapy improves recovery from spinal cord contusion. Ann Neurol 60:540-549.

Woodbury D, Schwarz EJ, Prockop DJ, Black IB (2000) Adult rat and human bone marrow stromal cells differentiate into neurons. J Neurosci Res 61:364-370.

Wrigley PJ, Gustin SM, Macey PM, Nash PG, Gandevia SC, Macefield VG, Siddall PJ, Henderson LA (2009) Anatomical changes in human motor cortex and motor pathways following complete thoracic spinal cord injury. Cereb Cortex 19:224-232.

Zhou L, Shine HD (2003) Neurotrophic factors expressed in both cortex and spinal cord induce axonal plasticity after spinal cord injury. J Neurosci Res 74:221-226.

Zurita M, Vaquero J, Bonilla C, Santos M, De Haro J, Oya S, Aguayo C (2008) Functional recovery of chronic paraplegic pigs after autologous transplantation of bone marrow stromal cells. Transplantation 86:845-853. 